\title{
Photoremovable Protecting Groups: Across the Light Spectrum to Near- Infrared Absorbing Photocages
}

\author{
Peter Štacko*ac and Tomáš Šolomek ${ }^{\star \mathrm{bc}}$
}

\begin{abstract}
We discuss the past decade of progress in the field of photoremovable protecting groups that allowed the development of photocages activatable by near-IR light and highlight the individual conceptual advancements that lead to general guidelines to design new such photoremovable protecting groups. We emphasize the importance of understanding the individual photochemical reaction mechanisms that was necessary to achieve this progress and provide an outlook of the subsequent steps to facilitate a swift translation of this research into clinical praxis. Since this issue of CHIMIA is dedicated to the late Prof. Thomas Bally, we decided to provide a personal perspective on the field to which he contributed himself. We tried to write this review with the general readership of CHIMIA in mind in a hope to pay a tribute to the extraordinary dedication and clarity with which Thomas Bally used to explain abstract chemical concepts to his students or colleagues. We are uncertain whether we matched such challenge but we believe that he would have liked such approach very much.
\end{abstract}

Keywords: Photocages · Photochemistry · Photoremovable protecting groups

Peter Štacko was born in 1987 in Slovakia. He received his Master's degree in Organic Chemistry from Masaryk University in Brno, Czechia (2011). Following a short internship in Hoffmann La Roche, Basel and an Erasmus stay in the Netherlands, he moved to Groningen to pursue his $\mathrm{PhD}$ at the Rijkuniversiteit Groningen in the group of Prof. Ben L. Feringa (2012-2016). Throughout his $\mathrm{PhD}$, he explored the translational and rotational motion on nanoscale using molecular motors and machines. In 2017, Peter received a Marie-Curie-funded fellowship (SoMoPro) to work as a postdoctoral fellow with Prof. Petr Klán at Masaryk University, Czech Republic on gasotransmitter-donors (CO, $\mathrm{H}_{2} \mathrm{~S}$ ) actuated with light. As of December 2020, Peter started his independent research career at the University of Zurich, funded by the Ambizione fellowship from the Swiss National Science Foundation, and hosted in the group of Prof. Cristina Nevado.

Tomáš Šolomek was born in 1985 in Slovakia. He studied at the Masaryk University in Brno (Czechia), where he also started his doctoral research in the laboratory of organic photochemistry with Prof. Petr Klán in 2009. After a year-long stay in the group of Prof. Petr Slavíček (2009-2010) at the University of Chemistry and Technology in Prague, he commenced (2011) a joint-PhD program between Masaryk University and the University of Fribourg under supervision of Prof. Klán and the late Prof. Thomas Bally. He combined experiments and theory to understand the chemistry of reactive intermediates generated by light or heat. In 2014, he moved to Basel for a short postdoctoral stay with Prof. Michal Juríček, a collaboration that lasts until present. Later (2015-2017), Tomáš was a SNSF postdoctoral researcher at Northwestern University in Chicago with Prof. Michael R. Wasielewski and started his independent research as an SNSF Ambizione fellow at the University of Basel in autumn 2017. He received funding from the ERC that allowed him to move his group and became an Assistant Professor at the University of Bern in April 2021.

\section{Introduction}

In 1966, Barltrop et al. described ${ }^{[1]}$ a new protecting group for organic synthesis that can be removed with UV light as a 'traceless reagent'. It uses the $o$-nitrobenzyl (oNB, Fig. 1a) group as the chromophore and the protected leaving groups (LGs) are attached via its benzylic position. Although a number of other such photoremovable protecting groups (PPGs) have appeared

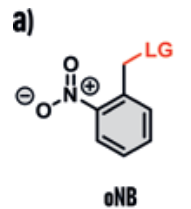

b)

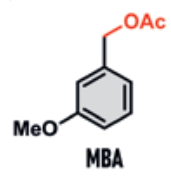

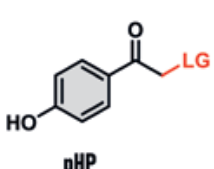

pHP

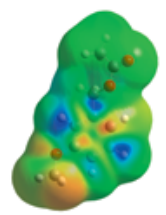

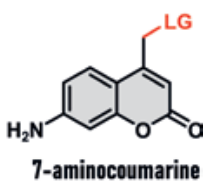

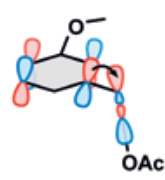

Fig. 1. a) Examples of important photoremovable protecting groups used widely in caged compounds. b) Illustration of the origin of the metaeffect in 3-methoxybenzyl acetate (MBA, left) with the $\mathrm{S}_{1}-\mathrm{S}_{0}$ electron density difference plot (middle, TD-B3LYP) highlighting electron density buildup (blue color) upon excitation in the meta-positions with respect to the methoxy group, and the overlap of the LUMO in MBA with the $\mathrm{CH}_{2}-$ OAc $\sigma$-antibonding orbital (right).

\footnotetext{
${ }^{*}$ Correspondence: Dr. P. Štacko ${ }^{\mathrm{ac}}$, Prof. T. Šolomek ${ }^{\mathrm{bc}}$, E-mail: peter.stacko@chem.uzh.ch; tomas.solomek@unibe.ch 
in the literature prior to ${ }^{[2-6]}$ or after ${ }^{[7]}$ this report, they found only a limited success in the total synthesis of natural products.

Yet, the concept of a light trigger, which breaks a chemical bond to selectively release a complex molecule proves invaluable to biological chemistry or medicine using so-called caged compounds or photocages (Fig. 2a). ${ }^{[8]}$ Light as the stimulus offers a number of advantages in biological settings because it can be controlled precisely in time and space. It does not interfere with other bio(chemical) stimuli and can avoid formation of harmful waste products. For example, the spatio-temporal control offered by a light trigger allowed tracking signal transduction in neural networks ${ }^{[9]}$ or sperm chemotaxis in all three dimensions. ${ }^{[10]}$ In medicine, administration of bioactive compounds, which interact with the molecular targets within human body to produce a pharmacological response, relies on the selectivity of the drug towards the intended targets. Imperfect selectivity results in side effects and decrease of the allowable dose. ${ }^{[11]}$ Regulation of the activity of the drug to reduce the off-target action can be achieved by an external trigger. A lot of effort has been recently devoted to conceive and implement drug-release systems controlled by temperature, ${ }^{[12]} \mathrm{pH},{ }^{[13]}$ light, ${ }^{[14]}$ ultrasound, ${ }^{[15]}$ magnetic ${ }^{[16-19]}$ and electric ${ }^{[20]}$ fields as exo- or endogenous stimuli. ${ }^{[21,22]}$ The demand for photocontrol of processes in vivo has led to the development of approaches that rely on metal-ligand systems, ${ }^{[23,24]}$ upconversion nanoparticles, ${ }^{[25-27]}$ NIR-absorbing plasmonic materials, ${ }^{[27]}$ twophoton uncaging ${ }^{[28]}$ or photoinduced electron transfer. ${ }^{[29]}$ However, direct activation and release from PPGs lay at the very beginning of all these efforts. In addition, PPGs allow activation and the effect of a drug to be separated unlike in the alternative strategy that has emerged in recent years, which uses a photoswitch incorporated

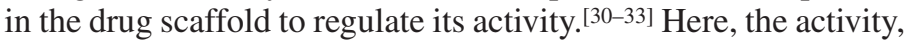
pharmacokinetic, and pharmacodynamic aspects of the modified active compound might be compromised as each such molecule essentially represents a new drug.

a)

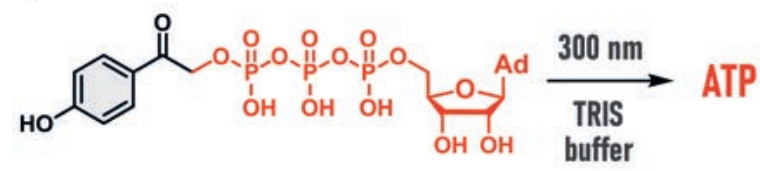

b)

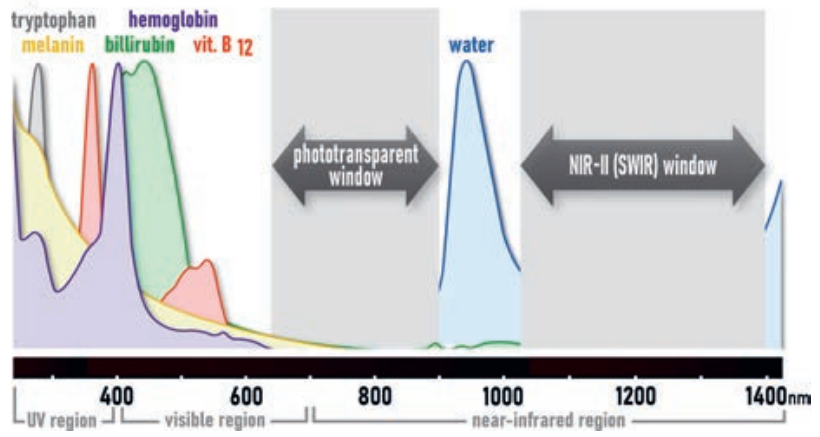

Fig. 2. a) Operating principle of cage compounds illustrated with pHP photoremovable protecting group releasing a molecule of ATP upon $300 \mathrm{~nm}$ excitation and b) phototransparent and NIR-II optical windows offering the highest tissue penetration depth; absorption spectra of selected biomolecules and that of water are highlighted.

The application of photocages can heavily benefit from the technological and instrumentation foundations built by translating photodynamic therapy (PDT) into medical practice. The efficiency and cost of light-emitting diodes have improved exponentially as forecast by Haitz's Law. ${ }^{[34]}$ Nowadays, cheap and portable light sources are readily available. Their reach can be further extended using optical fibers which can be terminated by microlenses or diffusers to improve light distribution. ${ }^{[35]}$ Such light-delivery devices are now routinely employed in PDT treatments and are ready for a straightforward repurposing.

Photoactivation in a biological system naturally puts a number of requirements on the properties of a PPG. We list here only three aspects, which we consider particularly important:

1) In biological chemistry, the rate constant of the release process $k_{\text {rel }}$ from a PPG must be higher than the rate constant of the dynamical event to be studied. This requires a thorough understanding of individual reaction mechanisms of PPGs and it represented an important incentive in the development of organic photochemistry. In some cases, such as in $\mathbf{0 N B}$, the release process is relatively slow and occurs from a ground-state intermediate formed upon irradiation. ${ }^{[36-38]}$ In other cases, the release takes place directly in the excited state and may lead to ultrafast $k_{\text {rel }}$ as reported for $p$-hydroxyphenacyl (pHP, Fig. 1a) PPG with good LGs, ${ }^{[39-41]}$ which we will discuss later. This allows to investigate even the most rapid processes in biology.

2) Photorelease from a PPG must be possible in water and the PPG or its photoproducts should be non-toxic. Here, pHP presented a major step forward in the development of PPGs because, unlike in $\mathbf{o N B}$, irradiation transforms the chromophore into non-toxic products and $\mathbf{p H P}$ is compatible with the aqueous environment. ${ }^{[41-43]}$ In fact, the presence of water is necessary for the photo-Favorskii process in $\mathbf{p H P}$ to provide an efficient heterolytic LG release. ${ }^{[40]}$

3) Despite the significant improvement in understanding the photochemical processes in many PPGs, the major challenge in the field was the development of PPGs that can be activated by near-infrared (NIR) light to adjust their absorption spectrum to the phototransparent or phototherapeutic window (650-900 nm, Fig. 2b). The irradiation wavelengths are restricted to the NIR region due to toxicity of the UV-light, the presence of hemoglobin and other biomolecules absorbing UV or visible light (e.g. melanin, bilirubin, vitamin B12), water (>900 nm), or tissue inhomogeneity responsible for light scattering. ${ }^{44,45]}$ The type of biological tissue, the content of water, fat, blood, and even the level of oxygen are all factors that affect the extent of light attenuation and depth of the tissue penetration. ${ }^{[46]}$ To put this into a perspective, $600 \mathrm{~nm}$ light penetrates human tissue up to $2-3 \mathrm{~mm}$, while $800 \mathrm{~nm}$ light up to a depth of 4-5 $\mathrm{mm}$.

\section{The Field Roughly a Decade Ago}

While no examples of PPGs absorbing NIR light existed a decade ago, a few instances of visible light absorbing groups were known. ${ }^{[7,47]}$ However, it was rather the onset of their absorption than an intense maximum that extended into the visible light region. Coumarine-derived PPGs are well-known examples. ${ }^{[41]}$ For instance, 7-aminocoumarinyl (Fig. 1) with an absorption spectrum protruding past $400 \mathrm{~nm}$ was found to release $\gamma$-aminobutyric acid (GABA) derivative as a LG upon irradiation in PBS buffer with $\sim 4 \%$ quantum yield (QY). ${ }^{[48]} \mathrm{A}$ rapid photoheterolysis in the singlet excited state forming an ion pair was identified in coumarines. ${ }^{[49]}$ Nevertheless, the photorelease QYs are relatively low and no straightforward way to improve them or to extend the absorption beyond blue light was known.

Concerning the first requirement described above, the high values of $k_{\text {rel }}$ should be achieved to avoid any interference of the release step with a dynamic process in chemical biology or the action of a drug. Therefore, one should aim at designing PPGs that uncage the substrate in the excited state to circumvent the relatively slow thermal release from a ground-state intermediate. However, there was a concern that the uncaging process directly in the excited state might not be compatible with the desired long wavelength of a NIR or even a visible photon because their energy 
is insufficient to trigger an efficient bond dissociation. This concern likely originated from a number of known photochemical reactions that typically involve formation of radical species. ${ }^{[50]}$ Simply, the bond energies are far too high and this would seriously restrict the type of protected substrates. Indeed, it was found in several instances that modification of an efficient PPG chromophore with additional substituents to extend its absorption to the visible light region resulted in diminished QYs of release. ${ }^{[7,41,51]}$ However, even many ground state heterolytic reactions in polar solvents possess activation energies that allow for a rapid LG cleavage. ${ }^{[52]}$ There is no specific physical law that forbids a heterolytic process on a low-energy excited state potential energy surface. Yet, the concern mentioned above persisted in the field. We think that one of the reasons is that the classification of photochemical reactions does not parallel the understanding achieved in classical organic chemistry. Often, photochemistry offers rather "unexpected or unpredictable" reactions, a notion that students can get from a basic course of organic photochemistry. ${ }^{[53]}$ For example, different spin states are often involved, such as a triplet state with two unpaired electrons. The presence of the unpaired electrons tempts one to assume that a triplet state reactivity exclusively involves radical reactions. Although it is often the case, it may be useful to think about the lowest energy triplet state as if it was a ground state, but just of a different multiplicity. Ionic reactions, bond heterolysis included, should not then be so surprising as a number of examples known to radicals or radical ions are well documented. ${ }^{[54]}$ In conjugated $\pi$-systems, the lowest triplet state has a well-defined electron configuration formed by promotion of an electron from the highest occupied MO (HOMO) to the lowest unoccupied MO (LUMO) while flipping its spin. In most cases, both the lowest triplet and singlet excited states are reasonably well described by the very same singly excited electron configuration. The only difference is in the spin of an electron. In such an approximation, one could expect that the shape of their potential energy surfaces could be similar with comparable reaction barriers. We will see below that this can indeed be the case, although important differences that stem from the different multiplicities do exist.

Generally, the rate of a simple heterolytic reaction depends on the extent of stabilization of the charges in the transition state offered by the solvent and the electronic nature of the carbenium ion and the departing LG. If the bond is polarized nearly to the extent observed in the transition state structure, the Hammond postulate predicts an early transition state with a relatively low activation energy and a facile bond cleavage. The Hammond postulate is expected to be invariant to the nature of the electronic state. ${ }^{[55,56]}$ Therefore, a change in the electron density upon excitation leading to a bond polarization (Fig. 1b) might lead to an efficient heterolysis. The reason for this effect is that excitation depletes electron density in the molecule in positions where the HOMO has the largest atomic orbital (AO) coefficients, while it builds up the electron density according to the distribution in the LUMO. If a LG is attached to the chromophore via a methylene $\left(\mathrm{CH}_{2}\right)$, the antibonding $\sigma-\mathrm{MO}$ of the $\mathrm{CH}_{2}-\mathrm{LG}$ bond inherits part of the extra electron density due to MO mixing with the LUMO of the chromophore. ${ }^{[57]}$ The $\mathrm{CH}_{2}-\mathrm{LG}$ group should be attached to a position in the chromophore with a high AO coefficient in the LUMO for a better MO mixing (overlap). Clearly, the very same position should ideally have a low coefficient in the HOMO. The situation is demonstrated in Fig. 1b where the electron density upon photoexcitation of 3-methoxybenzyl acetate (MBA) increases in the meta-position with respect to the methoxy group. This is the basis of the Zimmermann's meta-effect proposed by Howard E. Zimmerman already in 1963. ${ }^{[58-60]}$ We will see below how such MO mixing naturally appears in a number of PPGs based on a variety of chromophores. ${ }^{[57]}$ However, ten years ago, it was not obvious that popular PPGs such as pHP or coumarines had a lot in common due to the meta-effect. It was the detailed understanding of their photodynamics that offered a valuable set of lessons that can now be used to access PPGs employing new chromophores with high efficacy and with up to NIR light excitation.

\section{Lessons from the Photochemistry of oNB}

As we mentioned above, the release of LGs from $\mathbf{o N B}$ does not take place directly in the excited state but in the ground state from the aci-nitro (Fig. 3a) intermediate formed after a hydrogen atom transfer (HAT) by the nitro group, in which the excitation is mainly localized. ${ }^{[7,47,61]}$ The HAT process can occur in both the excited singlet or in the triplet state because a relatively large spin-orbit coupling leads to a high intersystem crossing (ISC) rate populating the triplet state in nitroaromatic compounds. ${ }^{[62,63]}$ Nevertheless, both spin channels result in the formation of acinitro, which subsequently releases the LG slowly with near unity efficiency in a sequence of well-studied thermally-activated steps. ${ }^{[36-38]}$ However, none of these steps could explain the measured values of the primary kinetic isotope effect ${ }^{[64]}$ and the unexpected dependence of the QY of the release on the nature of different LGs. For example, poor LGs, such as alcohols, are released with significantly higher QYs than far better LGs like carboxylic acids. These observations suggested that the excited state processes must determine the overall QY. We studied the correlation between the measured QYs on the nature of the LGs and found a correlation with the stabilization energy that the LGs can provide to 2-nitrobenzyl radicals. ${ }^{[65]}$ For example, a full benzylic radical develops upon HAT in the triplet state. We then used high-level quantum chemical calculations and proposed a model (Fig. 3b) that helps to explain all previous experimental observations in $\mathbf{~} \mathbf{N B}$ and provided a valuable and general lesson for the design of PPGs. ${ }^{[63]}$

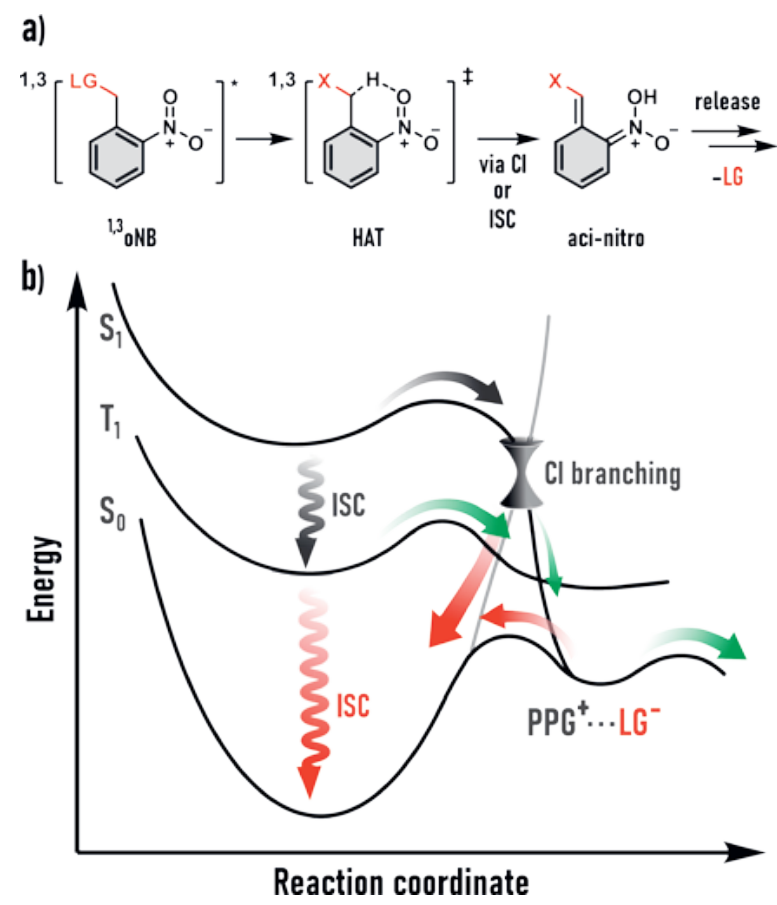

Fig. 3. a) Excited state reactions in oNB PPG with the hydrogen atom transfer (HAT) transition state and the formation of aci-nitro intermediate releasing the LGs and $b$ ) the corresponding potential energy surfaces for HAT in the excited singlet $\left(\mathrm{S}_{1}\right)$ and triplet $\left(\mathrm{T}_{1}\right)$ states highlighting the importance of the intersystem crossing (ISC) and the presence of the $S_{1} /$ $\mathrm{S}_{0}$ conical intersection $(\mathrm{Cl})$ and the excited state population branching into the productive (green arrow) and unproductive (red arrow) paths. Note that such $\mathrm{Cl}$ and branching is missing in the $\mathrm{T}_{1}$ state because it has a different spin symmetry than the $\mathrm{S}_{0}$ state. 
We found out that poor LGs offer a better stabilization to the nascent benzylic radical, which leads to earlier HAT transition states and, therefore, lower reaction barriers in $\mathrm{S}_{1}$ and $\mathrm{T}_{1}$ states. The barriers are comparable in both spin states, which demonstrates the validity of our former assumption about the similarity of the corresponding excited state PESs. The size of the barrier alters according to the Hammond postulate and has an important consequence on the efficiency of aci-nitro formation. If it is too low, nearly all excited molecules overcome the barrier in the singlet excited state and encounter a conical intersection (CI, Fig. 3b) that transfers them to the ground state soon after. At the CI, some excited state molecules will follow the reaction path forming the aci-nitro intermediate but some will get deactivated to the starting ground state oNB. The ratio of these two channels, called the branching ratio, is dictated by the dynamics in the vicinity of the CI. In $o$-nitrobenzaldehyde, a structurally related molecule, the branching ratio determined by excited state molecular dynamics calculations predicts only $\sim 30 \%$ of productive HATs. ${ }^{[66]}$ Thus, poor LGs with negligible HAT barriers will display comparable QYs that reflect the branching ratio at the CI. In addition, the primary ground state intermediates can follow the reverse reaction and return to the starting compound. This process is spin allowed and decreases the overall QY, although not in oNB. ${ }^{[36-38]}$ It is, however, particularly important for chromophore $\bullet \bullet$ LG contact or solvent-separated ion pairs that are formed in a photosolvolysis.

When a LG faces a high barrier in the singlet excited state, it can be siphoned to the triplet state by ISC. Triplet states are considerably longer lived because deactivation processes are spin forbidden. Therefore, a molecule that faced an impenetrable barrier on the singlet excited surface, and would be eventually deactivated by internal conversion or fluorescence, has much longer time to surpass a comparable barrier in the triplet state. There is no conical intersection between the triplet and the singlet ground state and the only process, omitting slow phosphorescence, that competes with the reaction is the triplet-to-singlet $\left(\mathrm{T}_{1} \rightarrow \mathrm{S}_{0}\right)$ ISC. In addition, once the barrier is overcome, the direct back reaction of the primary triplet intermediates to the singlet ground state of the photocage does not take place because it is also spin forbidden. Both the $\mathrm{S}_{1} \rightarrow \mathrm{T}_{1}$ and $\mathrm{T}_{1} \rightarrow \mathrm{S}_{0}$ ISCs are unusually fast in $\mathbf{o N B} \mathbf{N}^{[62]}$ but typically relatively slow in other organic chromophores. Due to efficient ISC in $\mathbf{o N B}$, the QYs of release do not correlate monotonically with the LG radical stabilization energies and the highest QYs are found for LGs that are at the sweet spot balancing the singlet and triplet reaction channels. ${ }^{[63,65]}$

Therefore, two lessons can be learned from the excited state reactivity in $\mathbf{O N B}$ that can be translated to the design of ultrafast and efficient photoheterolytic release of LGs: (A) Aim at releasing the $L G$ in the long-lived triplet state to maximize the quantum yield and (B) stabilize the nascent benzylic cation to increase the heterolytic $k_{r e l}$

\section{Lessons from the Photochemistry of pHP}

pHP (Fig. 1a) is derived from the phenacyl chromophore, which is known to undergo a rapid ISC because its singlet $\mathrm{n}, \pi^{*}$ and triplet $\pi, \pi^{*}$ excited states are close in energy.[50,67] Photoreactivity of $\mathbf{p H P}$ thus demonstrated that an efficient heterolysis in the triplet state was possible. ${ }^{[68]}$ Detailed studies of the photo-Favorskii reaction of pHP identified that the LG release accompanied by a concomitant deprotonation of the hydroxy group led to the formation of an intermediate, nature of which was debated for a long time. Jacob Wirz and coworkers from the University of Basel identified its spectroscopic signature and suggested its diradicaloid structure. ${ }^{[69]}$ Givens then proposed a series of nifty experiments to probe the formation of the intermediate by embedding the $\mathbf{~ p H P}$ chromophore into more strained hydroxyindanone and hydroxytetralone structures. ${ }^{[70]}$ Together with our transient absorption data and quantum chemical calculations, we could unambiguously characterize its structure (Fig. 4, row 2) and reactivity. ${ }^{[71]}$ The structure of this intermediate can be perceived as a $\pi$-extended analogue of a diradical, which one formally obtains by releasing a LG from the $\alpha$-carbon in acetate (Fig. 4, row 1). Inspection of the topology of the frontier MOs of such intermediates shows that they are isolobal with the oxyallyl diradical. ${ }^{[72]}$ In fact, the individual chromophores from which these diradicals are formed by a LG release share the same topology of frontier MOs (Fig. 4, right column) and display the build-up of electron density in the position to which<smiles>CC(=O)OCCCCCC(=O)O[Na]</smiles><smiles>c1ccccc1</smiles>

LUMO<smiles>c1ccccc1</smiles>

HOMO

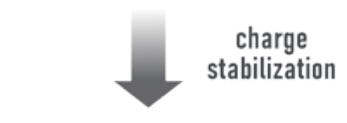<smiles>O=C([O-])c1ccc([O-])cc1</smiles>

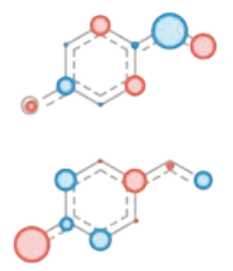

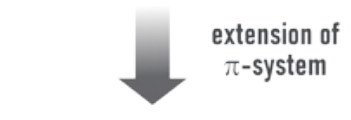<smiles>Cc1cc(=O)oc2cc([O-])ccc12</smiles><smiles></smiles>

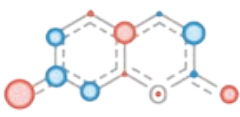

HOMO

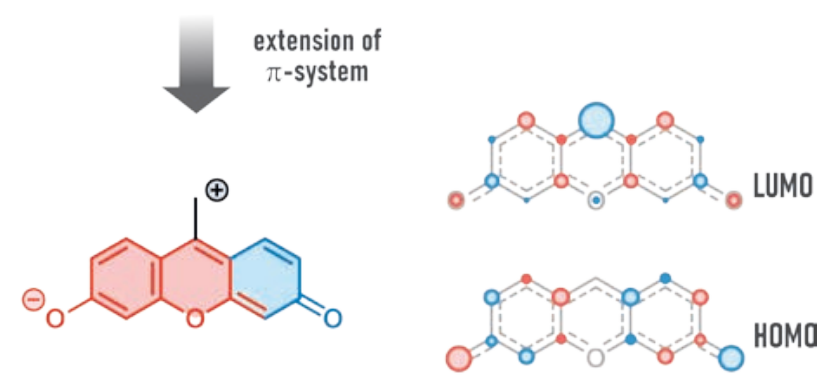

\section{isolobal} analogy
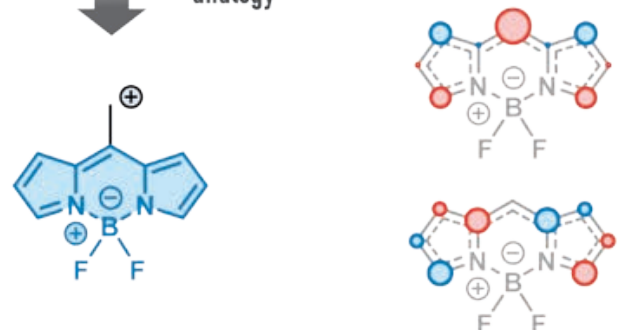

LUMO

HOMO

Fig. 4. (left column) Conceptual evolution of the structure of the primary intermediates based on their frontier molecular orbital characteristics. These are formed upon photoheterolysis of a LG from PPGs from the carbon atom that bears the positive charge. Note that these zwitterionic intermediates have a diradicaloid electronic structure as illustrated in row 1. The HOMO and the LUMO (right column) of the corresponding PPG chromophores highlighting the buildup of electron density in the position that carries the $\mathrm{CH}_{2}-\mathrm{LG}$ group (not shown for clarity of the MOs). 
the $\mathrm{CH}_{2}-\mathrm{LG}$ is attached in these chromophores. This corresponds to the Zimmermann's meta-effect that we discussed previously. Similarly, photoheterolysis in other known PPGs, such as in coumarines, also shares the same MOs characteristics. A LG release in these PPGs thus provides diradicals (cations in some cases) derived from oxyallyl ${ }^{[73]}$ and their formation can be related to the meta-effect. ${ }^{[57]}$ Indeed, these destabilized diradicals/cations that are formed from these PPGs were found by Winter and collaborators to have nearby CIs along the heterolysis reaction coordinate in the singlet excited state. ${ }^{[74]}$ Thus, the potential energy surfaces of such PPGs with efficient singlet or triplet heterolysis are reminiscent of the $\mathbf{~} \mathbf{N B}$ scenario (Fig. 3b) that we discussed above and reinforce the importance of the two lessons (A and $\mathrm{B}$ ) that we learnt regarding the presence of CIs and the barrier heights. The understanding of the photo-Favorskii process in pHP thus offered another critical lesson: (C) isolobal analogy relates all diradical/cationic intermediates formed by heterolytic $L G$ release to the oxyallyl diradical and connects the reactivity of their PPG precursors via the meta-effect.

\section{The First Photocage Activated by Green Light}

The three Lessons A-C form a design platform to improve the existing or to develop new PPGs with light absorption that can extend to visible or even NIR region. The first such attempt was undertaken by Wirz who, together with the group of Klán, extended the structure of coumarines and designed a xanthenebased PPG (Fig. 4, row 4). ${ }^{[75]}$ A successful LG release triggered by green light $\left(\lambda_{\mathrm{ex}}=520 \mathrm{~nm}\right)$ represented a major step forward in the field. However, it was found that the photocage formed a stable 1:1 complex with a molecule of DDQ that was used in the challenging synthesis of the xanthene PPG, which did not allow to unambiguously demonstrate whether the LG release followed a photoheterolysis pathway or was effected by an electron transfer event. Nevertheless, the xanthene platform was further developed into a metal-free (and DDQ-free) CO releasing molecule (CORM) ${ }^{[76]}$

\section{BODIPY}

In 2015, in full accord with Lesson C, Weinstain and Winter independently made a seminal contribution to the field, which has spurred the search for the perfect PPG. They reported a PPG based on the BODIPY scaffold (Fig. 4, row 5 and Fig. 5) capable of direct photoheterolytic release of various LGs upon irradiation with green light $\left(\lambda_{\max } \sim 545 \mathrm{~nm}\right) .{ }^{[77,78]}$ The motif eventually proved to be highly versatile with a relatively straightforward synthesis and enabled photouncaging of chlorides, carboxylates, amines, alcohols, $S$ - and $O$-thiocarbonates, thiocarboxylates, and xanthates. ${ }^{[79,80]}$

Although the initial QYs of the release was relatively low, on the order of $\Phi_{\mathrm{R}} \sim 10^{-4}$, the follow-up structure-reactivity study evaluated the factors crucial for its improvement. ${ }^{[79]}$ Introduction of electron-withdrawing groups such as halogen atoms, formyl groups or sulfonates impeded or, in some cases, fully halted the reactivity. Electron-donating alkyl groups, or dialkylborano analogues exhibited up to 30 -fold increase in $\Phi_{\mathrm{R}}$ (Fig. 5). The increased stabilization of the putative carbenium ion (Fig. 4, row 5 ) and deceleration of the ion pair recombination both play a role in the improved efficacies (Lesson B). The photoheterolysis in BODIPY-based PPGs was shown to proceed both via the singlet and triplet excited states. In case of good LGs, such as $\mathrm{Cl}^{-}$, the release occurs in both channels with comparable efficiency. Mediocre LGs such as carboxylates are released exclusively from the triplet excited state, and the $\Phi_{\mathrm{R}}$ correlates with the increasing QY of $\mathrm{S}_{1} \rightarrow \mathrm{T}_{1}$ ISC (Lesson A). Eventually, $\Phi_{\mathrm{R}}$ of 0.32 for carboxylates was achieved using diiodo-BODIPY analogues. The liberation efficiency, in general, correlated well with the $\mathrm{p} K$ of the respective conjugated acids (Lesson B). Consequently, poor LGs, such as alcohols or amines, cannot be released directly. Their uncaging was facilitated by the use of carbonate or carbamate linkers, which improve the nucleofugacity of the LGs. However, the $\mathrm{LG}$ release then occurs via subsequent spontaneous $\mathrm{CO}_{2}$ release from liberated carbonates and carbamates to the corresponding alcohols or amines, respectively, a process that is relatively slow. All these observations provide credence to the generality of the three lessons derived from understanding the excited state reactivity in $\mathbf{~ N B}$ and $\mathbf{p H P}$. In addition, BODIPY could also be modified into a photoCORM, ${ }^{[81]}$ similar to xanthene, again, as the consequence of the related topologies of the frontier MOs.

Concurrently with these studies, major efforts were devoted to shifting the absorption maxima from $\sim 550 \mathrm{~nm}$ of the parent
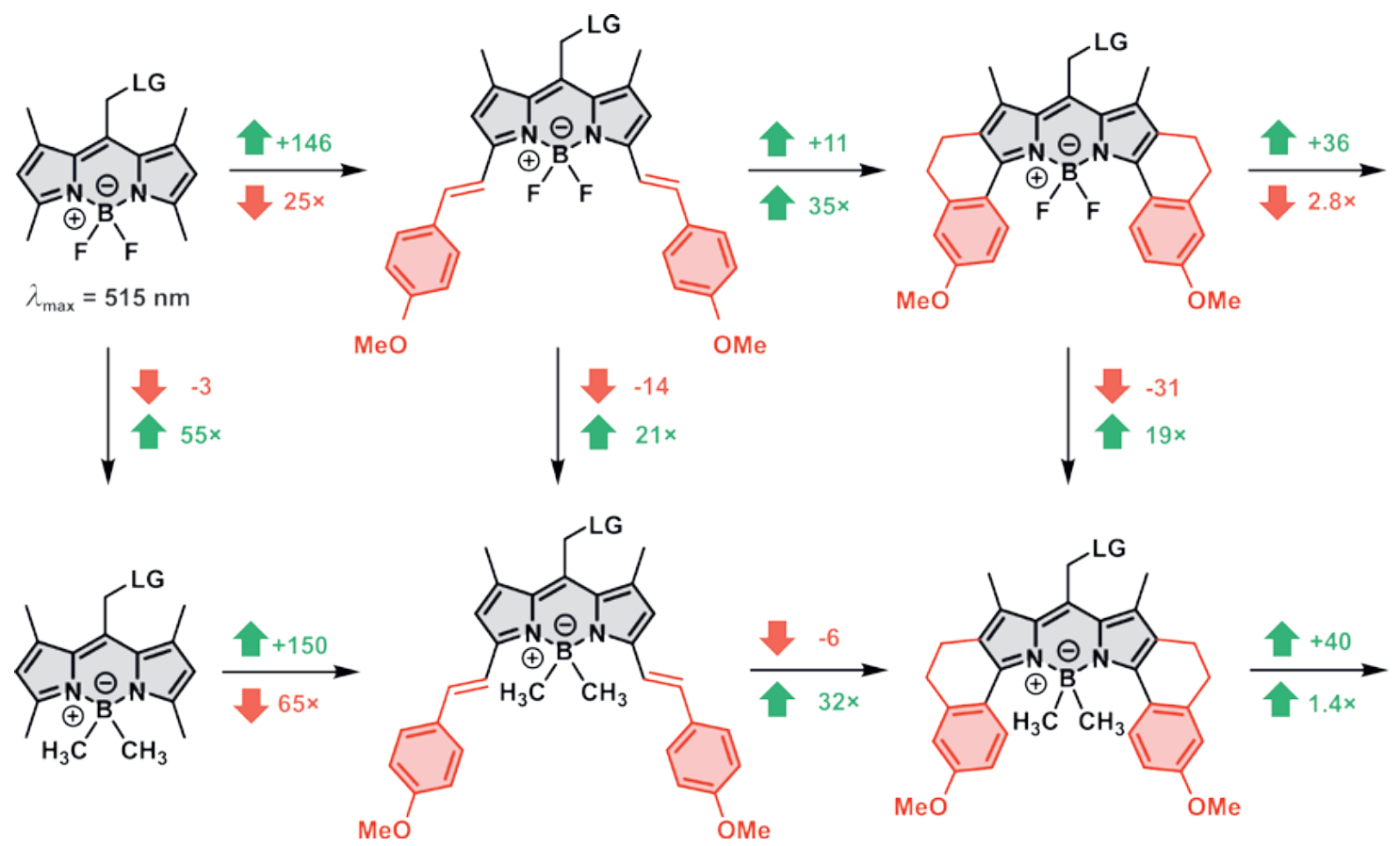
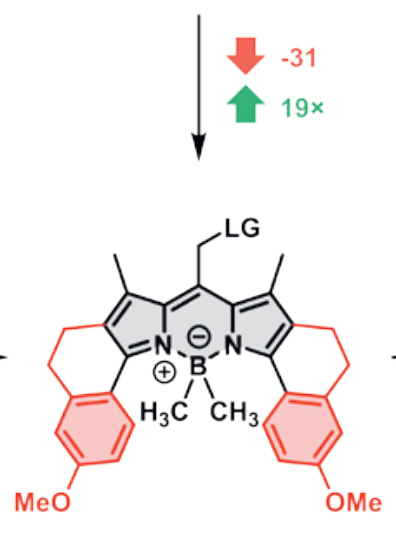
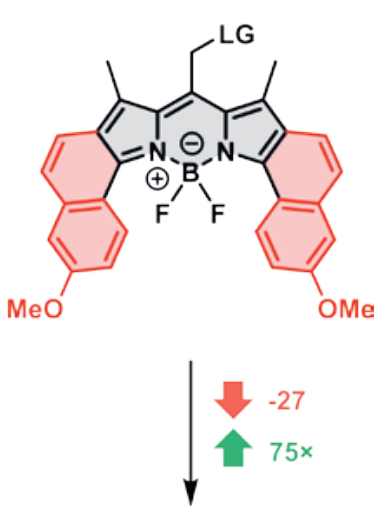

Fig. 5. Influence of the structural modifications on the absorption maxima (top number, in $\mathrm{nm}$ ) and quantum yield of the release (bottom number) in BODIPY-based PPGs. 
BODIPY to longer wavelengths. Appending styryl residues decorated with electron-donating groups onto the BODIPY core led to PPGs with absorption maxima at $640 \mathrm{~nm} \cdot{ }^{[82,83]}$ However, this approach introduced a number of shortcomings. The releasing efficiency was compromised by more than an order of magnitude and the chromophore was shown to be prone to photobleaching via the reaction of the alkenes with singlet oxygen. The decreased efficiency could be fully salvaged by exchange of the fluoro substituents on the boron atom for methyl groups (Fig. 5). Winter and co-workers recently introduced a class of ring-fused BODIPYs, which overcome the absorption limit and enter to the phototherapeutic window $\left(\lambda_{\text {max }}=709 \mathrm{~nm}\right)$, while maintaining relatively high efficacies. ${ }^{[84]}$ Their strategy to suppress the unproductive decay pathways further improved the release efficacies of the existing BODIPY PPGs up to an impressive $\Phi_{\mathrm{R}}=0.03$.

BODIPYs are also efficient sensitizers of singlet oxygen with QYs of ${ }^{1} \mathrm{O}_{2}$ generation of $\Phi_{\Delta}>0.3$, with iodo-substituted derivatives reaching values of up to 0.94. ${ }^{[85]}$ This raised genuine concerns with regard to the phototoxicity of BODIPY PPGs and a potential photooxidation of the cargo molecule ${ }^{[86]}$ because the BODIPY scaffold remains intact after the photorelease and produces a continuous supply of singlet oxygen upon irradiation.

Since their inception, BODIPY PPGs have been successfully used in various biological applications. Both photorelease of gasotransmitter $\mathrm{H}_{2} \mathrm{~S}$ and modulation of $\mathrm{Ca}^{2+}$ levels using caged histamine have been demonstrated in cellular environments. ${ }^{[77,83,87]}$ Uncaging of nitric oxide (NO) donor by light was shown to induce vasodilation of rat aorta in the report of Sortino and co-workers. ${ }^{[88]}$ Sitkowska $e t$. al. utilized BODIPY-protected dopamine to control the beating frequency of cardiomyocytes by irradiation with red light. ${ }^{[89]}$ Other noteworthy examples include targeted release of the protonophore 2,4-dinitrophenol in mitochondria, protein synthesis inhibitor puromycin in the endoplasmic reticulum ${ }^{[90]}$ and photocontrolled delivery of cytotoxic chlorambucil and cathepsin B inhibitor to cells. ${ }^{[91,92]}$ Further efforts have also been devoted to the improvement of cellular uptake of BODIPY PPGs, enabling specific subcellular targeting, and to improve their solubility in water. $[87,90]$

\section{What lies ahead?}

The recent exciting contributions to the development of BODIPY photocages could suggest that the field has reached its goal with no obstacles left to overcome. However, there is still a long path to successfully implement such photocages, especially as small-molecule delivery systems in the therapeutical context, with a number of challenges and opportunities ahead. We address a few below.

\section{User-friendly Synthesis}

The synthesis of photoreleasing systems must be concise, user-friendly, scalable and preferably avoid laborious purification. Facile and versatile synthesis allows manipulation of the photochemical performance, or addressing properties pertaining to the biological applicability such as solubility, pharmacokinetic and pharmacodynamic profiles. The synthetic pathway should, therefore, be divergent and, ideally, enable introduction of the cargo molecules in the very last and straightforward synthetic step. This would provide a quick access to large libraries of caged biologically active compounds. It also reduces potential risks with the tolerance of functional groups within the cargo and significantly increases attractiveness and availability of photocages beyond chemical research fields. For instance, the ease of the synthesis is likely one of the factors behind the widespread success of oNB-based PPGs among biologists. Finally, photocages must become available in form of a ready-to-deploy toolkit.

\section{Conquering the Second Phototherapeutic Window}

Beyond $700 \mathrm{~nm}$, the absorption profile of human tissue remains relatively constant and it is perturbed only by the absorption band of water at $>900 \mathrm{~nm}$. On the contrary, light scattering, a major component of light attenuation, decreases with the fourth power of the irradiation wavelength. This gives rise to a second phototherapeutic window between 1000-1400 $\mathrm{nm}$ (NIR-II or SWIR). Recent technological progress facilitated exploring this region for bioimaging, which may enhance optical imaging techniques with unrivaled temporal and spatial resolution. ${ }^{[93-96]}$ The feasibility of NIR-II in vivo bioimaging was demonstrated using carbon nanotubes, ${ }^{[97]}$ quantum dots, ${ }^{[98]}$ rare-earth nanomaterials ${ }^{[99]}$ and small molecules. ${ }^{[100]}$ However, its full potential in terms of unprecedented deep penetration, high spatial resolution, multicolor imaging and fast acquisition rates was showcased only recently using indium-arsenide quantum dots. ${ }^{[101]}$ The authors quantified heartbeat and breathing rates in unrestrained, fully-awake animals, the metabolic turnover rates of lipoproteins in several organs simultaneously and constructed a detailed three-dimensional flow map of mouse brain vasculature. SWIR imaging was used also to perform excitation multiplexed imaging in awake animals. ${ }^{[102]}$

Even though leveraging the advantages of NIR-II light for PPG systems is probably not indispensable for their widespread application, the implications of developing such organic photocages would be significant. Both the spatial resolution and the light penetration ability (depth up to 10-12 $\mathrm{mm}$ ) would be substantially enhanced. The vertical $\mathrm{S}_{0}-\mathrm{T}_{1}$ gap of ${ }^{1} \mathrm{O}_{2}$ lies at $94.3 \mathrm{~kJ} \mathrm{~mol}^{-1}$ and corresponds to a forbidden singlet-triplet transition at $\sim 1270 \mathrm{~nm}$. ${ }^{103]}$ PPGs absorbing in the NIR-II region are, therefore, likely to be less efficient sensitizers of ${ }^{1} \mathrm{O}_{2}$ with improved phototoxicity profiles as a consequence. Self-sensitized photooxidation, a known major photodegradation pathway of the chromophores themselves, ${ }^{[104-107]}$ would also be suppressed. As of now, there are no reports of PPGs operating in this region and thus their development could herald a new era in the field.

\section{Maintaining the Release Efficacy and Battling the Non-Radiative Processes}

The efficiency of PPG systems must enable release of the cargo molecules upon exposure to light doses comparable to those used in PDT (50-100 $\mathrm{J} \mathrm{cm}^{-2}$ ), and within a reasonable timeframe (i.e. minutes to an hour). ${ }^{[108]}$ The so-called uncaging cross-section $\left(\varepsilon \Phi_{\mathrm{R}}\right)$ is often quoted to represent the measure of the photocage efficacy and is obtained as a product of the absorption coefficient $(\varepsilon)$ and $\Phi_{\mathrm{R}}$ of the photocage at a given wavelength. The commonly accepted value of uncaging cross-section required for biological applications is above $\sim 100 . .^{[7]}$ Given the strongly absorbing nature of PPGs in the visible and NIR region $\left(\varepsilon>50000 \mathrm{~mol}^{-1} \mathrm{dm}^{3} \mathrm{~cm}^{-1}\right)$, this imposes the lower boundary restriction on the QY of release, $\Phi_{\mathrm{R}}>10^{-3}$. On the other hand, $\Phi_{\mathrm{R}}$ values that exceed a few percent represent a limitation from the practical standpoint because it becomes difficult to handle such compounds under ambient light. ${ }^{[79]}$ The desirable values of $\Phi_{\mathrm{R}}$ may appear counterintuitive and underwhelming when compared to the QYs of ${ }^{1} \mathrm{O}_{2}$ generation observed in PDT systems $\left(\Phi_{\Delta}=0.3-0.7\right)$. However, the short lifetime of ${ }^{1} \mathrm{O}_{2}$ in aqueous media $(\sim 3 \mu \mathrm{s})$ causes a majority of singlet oxygen to be unavailable to react with the molecular machinery within the cells. As a consequence, the overall therapeutic efficacy is then comparable. [109]

The question of efficacy becomes increasingly important as the absorption maxima of PPGs extend further into the NIR or SWIR regions. The rate of non-radiative deactivation processes increases exponentially with the decreasing HOMO-LUMO energy gap. ${ }^{[110]}$ This phenomenon, also known as energy gap law, renders the excited state lifetimes much shorter, effectively reducing the time available for the productive photorelease 
events. Its effects are more pronounced with increasing solvent permittivity and further exacerbated in hydroxylic solvents such as aqueous media.[111,112] The energy gap law has been already recognized as the major factor responsible for low fluorescence quantum yields of fluorophores in the NIR and SWIR region. [104,105,111,113] In addition, water and alcohols have been recently recognized to quench the fluorescence of common NIR organic chromophores that also follows an energy gap law. ${ }^{[114]}$ The design of the future PPGs will thus have to face the same uphill battle against non-radiative processes. Designing PPGs with rapid ISC (Lesson A) could be one of the possible guidelines to avoid losing the excitation via thermalization or energy transfer to water.

Moving across the first or transitioning into the second phototherapeutic window opens up another interesting and important question: What is the actual limit for a photorelease in terms of the excitation wavelength? The energy of the photons is far below any bond energies preventing any homolytic reactions. However, regarding bond heterolysis, a stability limit of the photocages likely exists. The chemical bond designed to cleave upon excitation must be thermally stable to prevent spontaneous reaction in the dark. The extent of stability required depends on the exact application, but if we considered a half-life of 24 hours at $37^{\circ} \mathrm{C}$, then ground state solvolysis with activation energies $\sim 24$ $\mathrm{kcal} \mathrm{mol}^{-1}$ would prevent the photocage from practical application. Although the diradicals/cations in Fig. 4 are destabilized due to their MO topology, the energy of their analogues must be below the energy of the corresponding PPG excited singlet state from which they are formed to allow for an exergonic release. This likely limits the excitation wavelength to $\sim 1200 \mathrm{~nm}$, i.e. the middle of the second phototherapeutic window (Fig. 2b). Similarly, low energy triplet states could be thermally populated to a nonnegligible extent allowing detrimental reactions with oxygen in air. In addition, low-lying excited states may affect the reactivity of the photocage in the ground state by mixing the excited state character into the electronic nature of the PPG, similar to what has been observed in some diradicaloids, ${ }^{[115-117]}$ further enhancing the ground state reactivity and limiting the stability.

Tremendous progress has been made in the field of PPGs in the past decade. Ten years ago, PPGs were lingering at the boundary of UV and visible regions, owing mainly to coumarin-based systems and a few others. In the meantime, PPGs have conquered the visible part of the spectrum and stand today firmly at the frontiers of the NIR region. Several examples already demonstrated a successful application in this area and some of them have been showed to function also in vivo. Unfortunately, the current stateof-the-art still does not deliver on all of the aforementioned fronts at the same time, synthetic availability in particular. Some major challenges thus still lie ahead and the aspects formulated in this perspective remain to be tackled in the upcoming decade.

\section{Acknowledgement}

The authors thank Dr. Lenka Štacková for her assistance with creating the figures and Hana Janeková for fruitful suggestions on the manuscript. We thank Juraj Malinčík for calculating the electron density difference plot in Fig. 1. We thank for the financial support of our research from the Swiss National Science Foundation (SNSF, T.Š./PZ00P2_174175, P.Š./ PZ00P2_193425) and the European Research Council (ERC) under the European Union's Horizon 2020 research and innovation programme (Grant Agreement No. 949397).

Received: August 4, 2021

[1] J. A. Barltrop, P. J. Plant, P. Schofield, Chem. Commun. 1966, 22, 822, https://doi.org/10.1039/C19660000822.

[2] J. A. Barltrop, P. Schofield, Tetrahedron Lett. 1962, 3, 697, https://doi.org/10.1016/S0040-4039(00)70935-X.
[3] D. H. R. Barton, Y. L. Chow, A. Cox, G. W. Kirby, J. Chem. Soc. 1965 3571, https://doi.org/10.1039/JR9650003571.

[4] D. H. R. Barton, Y. L. Chow, A. Cox, G. W. Kirby, Tetrahedron Lett. 1962 , 3, 1055, https://doi.org/10.1016/S0040-4039(00)70957-9.

[5] J. W. Chamberlin, J. Org. Chem. 1966, 31, 1658, https://doi.org/10.1021/jo01343a516.

[6] J. A. Barltrop, P. Schofield, J. Chem. Soc. 1965, 4758, https://doi.org/10.1039/JR9650004758.

[7] P. Klán, T. Šolomek, C. G. Bochet, A. Blanc, R. Givens, M. Rubina, V. Popik, A. Kostikov, J. Wirz, Chem. Rev. 2013, 113, 119, https://doi.org/10.1021/cr300177k.

[8] In the bio-related scientific fields, the protected substrates with the photoremovable protecting group are often called caged compounds, photocages, or, generally, photoactivatable compounds.

[9] M. Goeldner, R. S. Givens, 'Dynamic Studies in Biology: Phototriggers, Photoswitches and Caged Molecules', Wiley-VCH. Weinheim, 2005.

[10] J. F. Jikeli, L. Alvarez, B. M. Friedrich, L. G. Wilson, R. Pascal, R. Colin, M. Pichlo, A. Rennhack, C. Brenker, U. B. Kaupp, Nat. Commun. 2015, 6 , 1, https://doi.org/10.1038/ncomms8985.

[11] I. R. Edwards, J. K. Aronson, Lancet 2000, 356, 1255 , https://doi.org/10.1016/S0140-6736(00)02799-9.

[12] Z. S. Al-Ahmady, W. T. Al-Jamal, J. V. Bossche, T. T. Bui, A. F. Drake, A. J. Mason, K. Kostarelos, ACS Nano 2012, 6, 9335, https://doi.org/10.1021/nn302148p.

[13] H. W. Sung, K. Sonaje, Z. X. Liao, L. W. Hsu, E. Y. Chuang, Acc. Chem. Res. 2012, 45, 619, https://doi.org/10.1021/ar200234q

[14] C. S. Linsley, B. M. Wu, Ther. Deliv. 2017, 8, 89, https://doi.org/10.4155/tde-2016-0060..

[15] S. R. Sirsi, M. A. Borden, Adv. Drug Deliv. Rev. 2014, 72, 3 https://doi.org/10.1016/j.addr.2013.12.010.

[16] S. Giri, B. G. Trewyn, M P. Stellmaker, V. S. Y. Lin, Angew. Chem. Int. Ed. 2005, 44, 5038, https://doi.org/10.1002/anie.200501819.

[17] E. Ruiz-Hernández, A. Baeza, M. Vallet-Regí, ACS Nano 2011, 5, 1259 , https://doi.org/10.1021/nn1029229

[18] C. R. Thomas, D. P. Ferris, J. H. Lee, E. Choi, M. H. Cho, E. S. Kim, J. F. Stoddart, J. S. Shin, J. Cheon, J. I. Zink, J. Am. Chem. Soc. 2010, 132, 10623, https://doi.org/10.1021/ja1022267.

[19] S. H. Hu, S. Y. Chen, X. Gao, ACS Nano 2012, 6, 2558 , https://doi.org/10.1021/nn205023w.

[20] Q. Yan, J. Yuan, Z. Cai, Y. Xin, Y. Kang, Y. Yin, J. Am. Chem. Soc. 2010, 132, 9268, https://doi.org/10.1021/ja1027502.

[21] S. Mura, J. Nicolas, P. Couvreur, Nat. Mater. 2013, 12, 991 https://doi.org/10.1038/nmat3776.

[22] S. Senapati, A. K. Mahanta, S. Kumar, P. Maiti, Signal Transduct. Target Ther. 2018, 3, 7, https://doi.org/10.1038/s41392-017-0004-3.

[23] R. M. Hughes, C. M. Marvin, Z. L. Rodgers, S. Ding, N. P. Oien, W J. Smith, D. S. Lawrence, Angew. Chem. Int. Ed. 2016, 55, 16080, https://doi.org/10.1002/anie.201609731.

[24] T. A. Shell, D. S. Lawrence, Acc. Chem. Res. 2015, 48, 2866, https://doi.org/10.1021/acs.accounts.5b00331.

[25] C. J. Carling, F. Nourmohammadian, J. C. Boyer, N. R. Branda, Angew Chem. Int. Ed. 2010, 49, 3782, https://doi.org/10.1002/anie.201000611.

[26] S. Wen, J. Zhou, K. Zheng, A. Bednarkiewicz, X. Liu, D. Jin, Nat. Commun. 2018, 9, 2415, https://doi.org/10.1038/s41467-018-04813-5.

[27] G. Chen, H. Qiu, P. N. Prasad, X. Chen, Chem. Rev. 2014, 114, 5161 https://doi.org/10.1021/cr400425h.

[28] S. Gug, F. Bolze, A. Specht, C. Bourgogne, M. Goeldner, J. F. Nicoud, Angew Chem. Int. Ed. 2008, 47, 9525, https://doi.org/10.1002/anie.200803964.

[29] D. E. Falvey, C. Sundararajan, Photochem. Photobiol. Sci. 2004, 3, 831, https://doi.org/10.1039/B406866A.

[30] J. Broichhagen, J. A. Frank, D. Trauner, Acc. Chem. Res. 2015, 48, 1947, https://doi.org/10.1021/acs.accounts.5b00129.

[31] M. Stein, S. J. Middendorp, V. Carta, E. Pejo, D. E. Raines, S. A Forman, E. Sigel, D. Trauner, Angew. Chem. Int. Ed. 2012, 51, 42, 10500, https://doi.org/10.1002/anie.201205475

[32] K. Hüll, J. Morstein, D. Trauner, Chem. Rev. 2018, 118, 10710, https://doi.org/10.1021/acs.chemrev.8b00037.

[33] M. M. Lerch, M. J. Hansen, G. M. van Dam, W. Szymanski, B. L. Feringa, Angew. Chem. Int. Ed. 2016, 55, 10978, https://doi.org/10.1002/anie.201601931.

[34] R. V. Steele, Nat. Photonics 2007, 1, 25 , https://doi.org/10.1038/nphoton.2006.44.

[35] M. M. Kim, A. Darafsheh, Photochem. Photobiol. 2020, 96, 280 https://doi.org/10.1111/php.13219.

[36] Y. V. Il'ichev, J. Phys. Chem. A 2003, 107, 10159, https://doi.org/10.1021/jp0357121.

[37] Y. V. Il'ichev, J. Wirz, J. Phys. Chem. A 2000, 104, 7856 , https://doi.org/10.1021/jp000261v

[38] M. Schwörer, J. Wirz, Helv. Chim. Acta 2001, 84, 1441, https:// doi.org/10.1002/1522-2675(20010613)84:6<1441::AID HLCA1441>3.0.CO;2-W. 
[39] C. Ma, W. M. Kwok, W. S. Chan, Y. Du, J. T. W. Kan, P. H. Toy, D. L. Phillips, J. Am. Chem. Soc. 2006, 128, 2558, https://doi.org/10.1021/ja0458524.

[40] R. S. Givens, D. Heger, B. Hellrung, Y. Kamdzhilov, M. Mac, P. G. Conrad, E. Cope, J. I. Lee, J. F. Mata-Segreda, R. L. Schowen, J. Wirz, J. Am. Chem. Soc. 2008, 130, 3307, https://doi.org/10.1021/ja7109579.

[41] R. S. Givens, M. Rubina, J. Wirz, Photochem. Photobiol. Sci. 2012, 11, 472, https://doi.org/10.1039/C2PP05399C.

[42] C. H. Park, R. S. Givens, J. Am. Chem. Soc. 1997, 119, 2453, https://doi.org/10.1021/ja9635589.

[43] R. S. Givens, C. H. Park, Tetrahedron Lett. 1996, 37, 6259, https://doi.org/10.1016/0040-4039(96)01390-1.

[44] T. G. Phan, A. Bullen, Immunol. Cell Biol. 2010, 88, 438, https://doi.org/10.1038/icb.2009.116.

[45] Y.T. Lim, S. Kim, A. Nakayama, N. E. Stott, M. G. Bawendi, J. V. Frangioni, Mol. Imaging 2003, 2, 50, https://doi.org/10.1162/153535003765276282.

[46] S. L. Jacques, 'Physics in Medicine and Biology', IOP Publishing June 7, 2013, p R37.

[47] R. Weinstain, T. Slanina, D. Kand, P. Klán, Chem. Rev. 2020, 120, 13135 , https://doi.org/10.1021/acs.chemrev.0c00663.

[48] B. Cürten, P. H. M. Kullmann, M. E. Bier, K. Kandler, B. F. Schmidt, Photochem. Photobiol. 2007, 81, 641, https://doi.org/10.1111/j.1751-1097.2005.tb00238.x.

[49] R. Schmidt, D. Geissler, V. Hagen, J. Bendig, J. Phys. Chem. A 2007, 111, 5768, https://doi.org/10.1021/jp071521c.

[50] P. Klán, J. Wirz, 'Photochemistry of Organic Compounds: From Concepts to Practice', 1st ed.; John Wiley \& Sons Ltd., Chichester, 2009.

[51] R. S. Givens, K. Stensrud, P. G. Conrad, A. L. Yousef, C. Perera, S. N. Senadheera, D. Heger, J. Wirz, Can. J. Chem. 2011, 89, 364, https://doi.org/10.1139/V10-143.

[52] N. Streidl, B. Denegri, O. Kronja, H. Mayr, Acc. Chem. Res. 2010, 43, 1537, https://doi.org/10.1021/ar100091m.

[53] Frankly, this was also the case of the present authors.

[54] M. Cybularczyk-Cecotka, J. Szczepanik, M. Giedyk, Nat. Catal. 2020, 3, 872, https://doi.org/10.1038/s41929-020-00515-8

[55] The Hammond postulate is a hypothesis in physical-organic chemistry that relates the structural similarity of two consecutive points on a reaction coordinate, e.g., a transition state and a subsequent (or prior) intermediate, and their energies. If their energy content is similar, their interconversion will involve only a small reorganization of the structure. Although Hammond did not originally study the validity of this postulate for excited state reactions, instances where it applies in the excited singlet state ${ }^{[63]}$ or in the triplet state ${ }^{[56,63]}$ are known. Because the postulate relates consecutive geometrical points on the same energy surface, it is expected to be valid on any adiabatic surface (singlet, doublet, triplet, etc.) unless the electron configuration between the two points on the surface changes abruptly, for instance, due to a surface crossing. However, it would be desirable to test the validity of the Hammond postulate on a larger number of excited state systems to demonstrate its broad applicability known to singlet ground state reactions.

[56] C. G. Bochet, F. M. Harvey, Chem. Sci. 2021, 12, 599, https://doi.org/10.1039/D0SC04370B.

[57] T. Šolomek, J. Wirz, P. Klán, Acc. Chem. Res. 2015, 48, 3064, https://doi.org/10.1021/acs.accounts.5b00400.

[58] H. E. Zimmerman, S. Somasekhara, J. Am. Chem. Soc. 1963, 85, 922, https://doi.org/10.1021/ja00890a020.

[59] H. E. Zimmerman, J. Am. Chem. Soc. 1995, 117, 8988, https://doi.org/10.1021/ja00140a014.

[60] T. Schmierer, S. Laimgruber, K. Haiser, K. Kiewisch, J. Neugebauer, P. Gilch, Phys. Chem. Chem. Phys. 2010, 12, 15653, https://doi.org/10.1039/C004025H.

[61] R. W. Yip, D. K. Sharma, R. Giasson, D. Gravel, J. Phys. Chem. 1985, 89, 5328, https://doi.org/10.1021/j100271a002.

[62] M. Takezaki, N. Hirota, M. Terazima, J. Phys. Chem. A 1997, 101, 3443, https://doi.org/10.1021/jp963095t.

[63] T. Šolomek, C. G. Bochet, T. Bally, Chem. Eur. J. 2014, 20, 8062, https://doi.org/10.1002/chem.201303338.

[64] A. Blanc, C. G. Bochet, J. Am. Chem. Soc. 2004, 126, 7174, https://doi.org/10.1021/ja049686b.

[65] T. Šolomek, S. Mercier, T. Bally, C. G. Bochet, Photochem. Photobiol. Sci. 2012, 11, 548, https://doi.org/10.1039/C1PP05308F.

[66] V. Leyva, I. Corral, F. Feixas, A. Migani, L. Blancafort, J. GonzálezVázquez, L. González, Phys. Chem. Chem. Phys. 2011, 13, 14685 , https://doi.org/10.1039/C1CP20620F.

[67] W. H. Fang, D. L. Phillips, ChemPhysChem 2002, 3, 889, https://doi.org/10.1002/1439-7641(20021018)3:10<889::AIDCPHC889>3.0.CO;2-U.

[68] J. C. Anderson, C. B. Reese, Tetrahedron Lett. 1962, 3, 1, https://doi.org/10.1016/s0040-4039(00)62031-2.
[69] R. S. Givens, D. Heger, B. Hellrung, Y. Kamdzhilov, M. Mac, P. G. Conrad, E. Cope, J. I. Lee, J. F. Mata-Segreda, R. L. Schowen, J. Wirz, J. Am. Chem. Soc. 2008, 130, 3307, https://doi.org/10.1021/ja7109579.

[70] V. B. Kammath, T. Šolomek, B. P. Ngoy, D. Heger, P. Klán, M. Rubina, R. S. Givens, J. Org. Chem. 2013, 78, 1718, https://doi.org/10.1021/jo300850a.

[71] T. Solomek, D. Heger, B. P. Ngoy, R. S. Givens, P. Klán, J. Am. Chem. Soc. 2013, 135, 15209, https://doi.org/10.1021/ja407588p

[72] T. Ichino, S. M. Villano, A. J. Gianola, D. J. Goebbert, A. Sanov, L. Velarde, S. J. Blanksby, X. Zhou, D. A. Hrovat, W. T. Borden, W. C. Lineberger Angew. Chem. Int. Ed. 2009, 48, 8509, https://doi.org/10.1002/ anie. 200904417.

[73] T. R. Albright, A. H. Winter, J. Am. Chem. Soc. 2015, 137, 3402, https://doi.org/10.1021/jacs.5b00707.

[74] A. T. Buck, C. L. Beck, A. H. Winter, J. Am. Chem. Soc. 2014, 136, 8933 https://doi.org/10.1021/ja501777r.

[75] P. Šebej, J. Wintner, P. Müller, T. Slanina, J. Al Anshori, L. A. P. Antony, P. Klán, J. Wirz, J. Org. Chem. 2013, 78, 1833 , https://doi.org/10.1021/jo301455n.

[76] L. A. P. Antony, T. Slanina, P. Šebej, T. Šolomek, P. Klán, Org. Lett. 2013 15, 4552, https://doi.org/10.1021/o14021089

[77] N. Rubinstein, P. Liu, E. W. Miller, R. Weinstain, Chem. Commun. 2015, 51, 6369, https://doi.org/10.1039/C5CC00550G.

[78] P. P. Goswami, A. Syed, C. L. Beck, T. R. Albright, K. M. Mahoney, R. Unash, E. A. Smith, A. H. Winter, J. Am. Chem. Soc. 2015, 137, 3783, https://doi.org/10.1021/jacs.5b01297.

[79] T. Slanina, P. Shrestha, E. Palao, D. Kand, J. A. Peterson, A. S. Dutton, N. Rubinstein, R. Weinstain, A. H. Winter, P. Klán, J. Am. Chem. Soc. 2017 139, 15168, https://doi.org/10.1021/jacs.7b08532.

[80] K. Sitkowska, B. L. Feringa, W. Szymański, J. Org. Chem. 2018, 83, 1819 , https://doi.org/10.1021/ar4000357.

[81] E. Palao, T. Slanina, L. Muchová, T. Šolomek, L. Vítek, P. Klán, J. Am. Chem. Soc. 2016, 138, 126, https://doi.org/10.1021/jacs.5b10800.

[82] J. A. Peterson, C. Wijesooriya, E. J. Gehrmann, K. M. Mahoney, P. P. Goswami, T. R. Albright, A. Syed, A. S. Dutton, E. A. Smith, A. H. Winter, J. Am. Chem. Soc. 2018, 140, 7343, https://doi.org/10.1021/jacs.8b04040.

[83] P. Štacko, L. Muchová, L. Vítek, P. Klán, Org. Lett. 2018, 20, 4907, https://doi.org/10.1021/acs.orglett.8b02043.

[84] P. Shrestha, K. C. Dissanayake, E. J. Gehrmann, C. S. Wijesooriya, A. Mukhopadhyay, E. A. Smith, A. H. Winter, J. Am. Chem. Soc. 2020, 142, 15505, https://doi.org/10.1021/jacs.0c07139.

[85] R. Prieto-Montero, A. Prieto-Castañeda, R. Sola-Llano, A. R. Agarrabeitia, D. García-Fresnadillo, I. López-Arbeloa, A. Villanueva, M. J. Ortiz, S. de la Moya, V. Martínez-Martínez, Photochem. Photobiol. 2020, 96, 458, https://doi.org/10.1111/php.13232.

[86] T. Rodat, M. Krebs, A. Döbber, B. Jansen, A. Steffen-Heins, K. Schwarz, C. Peifer, Photochem. Photobiol. Sci. 2020, 19, 1319, https://doi.org/10.1039/D0PP00097C.

[87] D. Kand, P. Liu, M. X. Navarro, L. J. Fischer, L. Rousso-Noori, D. Friedmann-Morvinski, A. H. Winter, E. W. Miller, R. Weinstain, J. Am. Chem. Soc. 2020, 142, 4970, https://doi.org/10.1021/jacs.9b13219.

[88] M. Blangetti, A. Fraix, L. Lazzarato, E. Marini, B. Rolando, F. Sodano, R. Fruttero, A. Gasco, S. Sortino, Chem. Eur. J. 2017, 23, 9026, https://doi.org/10.1002/chem.201701889.

[89] K. Sitkowska, M. F. Hoes, M. M. Lerch, L. N. Lameijer, P. Van Der Meer, W. Szymański, B. L. Feringa, Chem. Commun. 2020, 56, 5480, https://doi.org/10.1039/D0CC02178D.

[90] D. Kand, L. Pizarro, I. Angel, A. Avni, D. FriedmannMorvinski, R. Weinstain, Angew. Chem. Int. Ed. 2019, 58, 4659, https://doi.org/10.1002/anie.201900850.

[91] M. Liu, J. Meng, W. Bao, S. Liu, W. Wei, G. Ma, Z. Tian, ACS Appl. Bio Mater. 2019, 2, 3068, https://doi.org/10.1021/acsabm.9b00356.

[92] N. P. Toupin, K. Arora, P. Shrestha, J. A. Peterson, L. J. Fischer, E. Rajagurubandara, I. Podgorski, A. H. Winter, J. J. Kodanko, ACS Chem. Biol. 2019, 14, 2833, https://doi.org/10.1021/acschembio.9b00711.

[93] H.Zhang, D. Salo, D. M. Kim, S. Komarov, Y.-C. Tai, M. Y. Berezin, J. Biomed. Opt. 2016, 21, 126006, https://doi.org/10.1117/1.JBO.21.12.126006.

[94] J. A. Carr, M. Aellen, D. Franke, P. T. C. So, O. T. Bruns, M. G. Bawendi, Proc. Natl. Acad. Sci. U. S. A. 2018, 115, 9080, https://doi.org/10.1073/pnas.1803210115.

[95] J. A. Carr, D. Franke, J. R. Caram, C. F. Perkinson, M. Saif, V. Askoxylakis, M. Datta, D. Fukumura, R. K. Jain, M. G. Bawendi, O. T. Bruns, Proc. Natl. Acad. Sci. U. S. A. 2018, 115, 4465, https://doi.org/10.1073/pnas.1718917115.

[96] E. Thimsen, B. Sadtler, M. Y. Berezin, Nanophotonics 2017, 6, 1043 https://doi.org/10.1515/nanoph-2017-0039.

[97] K. Welsher, Z. Liu, S. P. Sherlock, J. T. Robinson, Z. Chen, D. Daranciang, H. Dai, Nat. Nanotechnol. 2009, 4, 773 https://doi.org/10.1038/nnano.2009.294.

[98] G. Hong, J. T. Robinson, Y. Zhang, S. Diao, A. L. Antaris, Q. Wang, H. Dai, Angew. Chem. Int. Ed. 2012, 51, 9818 , https://doi.org/10.1002/anie.201206059. 
[99] D. J. Naczynski, M. C. Tan, M. Zevon, B. Wall, J. Kohl, A. Kulesa, S. Chen, C. M. Roth, R. E. Riman, P. V. Moghe, Nat. Commun. 2013, 4, 1, https://doi.org/10.1038/ncomms3199.

[100] Z. Tao, G. Hong, C. Shinji, C. Chen, S. Diao, A. L. Antaris, B Zhang, Y. Zou, H. Dai, Angew. Chem. Int. Ed. 2013, 52, 13002, https://doi.org/10.1002/anie.201307346.

[101] O. T. Bruns, T. S. Bischof, D. K. Harris, D. Franke, Y. Shi, L. Riedemann, A. Bartelt, F. B. Jaworski, J. A. Carr, C. J. Rowlands, M. W. B. Wilson, O. Chen, H. Wei, G. W. Hwang, D. M. Montana, I. Coropceanu, O. B. Achorn, J. Kloepper, J. Heeren, P. T. C. So, D. Fukumura, K. F. Jensen, R. K. Jain, M. G. Bawendi, Nat. Biomed. Eng. 2017, 1, 1, https://doi.org/10.1038/s41551-017-0056.

[102] E. D. Cosco, A. L. Spearman, S. Ramakrishnan, J. G. P. Lingg, M. Saccomano, M. Pengshung, B. A. Arús, K. C. Y. Wong, S. Glasl, V. Ntziachristos, M. Warmer, R. R. McLaughlin, O. T. Bruns, E. M. Sletten, Nat. Chem. 2020, 12 , 1123, https://doi.org/10.1038/s41557-020-00554-5.

[103] C. Schweitzer, R. Schmidt, Chem. Rev. 2003, 103, 1685 , https://doi.org/10.1021/cr010371d.

[104] L. Stacková, E. Muchová, M. Russo, P. Slavíček, P. Štacko, P. Klán, J. Org. Chem. 2020, 85, 9776, https://doi.org/10.1021/acs.joc.0c01104.

[105] L. Štacková, P. Štacko, P. Klán, J. Am. Chem. Soc. 2019, 141, 7155, https:// doi.org/10.1021/jacs.9b02537.

[106] L. Štacková, M. Russo, L. Muchová, V. Orel, L. Vítek, P. Štacko, P. Klán, Chem. Eur. J. 2020, 26, 13184, https://doi.org/10.1002/chem.202003272.

[107] R. R. Nani, J. A. Kelley, J. Ivanic, M. J. Schnermann, Chem. Sci. 2015, 6 , 6556, https://doi.org/10.1039/C5SC02396C.

[108] M. M. Kim, A. Darafsheh, Photochem. Photobiol. 2020, 96, 280, https://doi. org/10.1111/php.13219.

[109] S. Hatz, J. D. C. Lambert, P. R. Ogilby, Photochem. Photobiol. Sci. 2007, 6, 1106, https://doi.org/10.1039/B707313E
[110] B. R. Henry, W. Siebrand, 'Organic Molecular Photophysics', Wiley-VCH Verlag GmbH, 1973.

[111] S. S. Matikonda, G. Hammersley, N. Kumari, L. Grabenhorst, V. Glembockyte, P. Tinnefeld, J. Ivanic, M. Levitus, M. J. Schnermann, J. Org. Chem. 2020, 85, 5907, https://doi.org/10.1021/acs.joc.0c00236.

[112] J. V. Caspar, B. P. Sullivan, E. M. Kober, T. Meyer, J. Chem. Phys. Lett. 1982 91, 91, https://doi.org/10.1016/0009-2614(82)80114-0.

[113] E. D. Cosco, H. C. Friedman, T. L. Atallah, S. Jia, E. M. Sletten, J. R. Caram, ChemRxiv 2021, https://doi.org/10.26434/chemrxiv.14374493.v1.

[114] J. Maillard, K. Klehs, C. Rumble, E. Vauthey, M. Heilemann, A. Fürstenberg, Chem. Sci. 2021, 12, 1352 https://doi.org/10.1039/D0SC05431C.

[115] T. Šolomek, P. Ravat, M. Juríček, Trends Chem. 2019, 1, 705, https://doi.org/10.1016/j.trechm.2019.08.005

[116] T. Śolomek, P. Ravat, Z. Mou, M. Kertesz, M. Juríček J. Org. Chem. 2018, 83, 4769, https://doi.org/10.1021/acs.joc.8b00656.

[117] R. P. Steiner, J. Michl, J. Am. Chem. Soc. 1978, 100, 6413, https://doi.org/10.1021/ja00488a023.

\section{License and Terms}

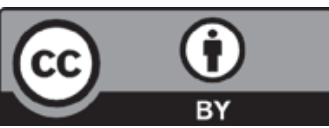

This is an Open Access article under the terms of the Creative Commons Attribution License CC BY 4.0. The material may not be used for commercial purposes.

The license is subject to the CHIMIA terms and conditions: (http:// chimia. ch/component/sppagebuilder/?view = page \&id=12).

The definitive version of this article is the electronic one that can be found at https://doi.org/10.2533/chimia.2021.873 